\title{
Warpage Optimisation on the Moulded Part with Conformal Cooling Channels using Response Surface Methodology (RSM) and Glowworm Swarm Optimisation (GSO)
}

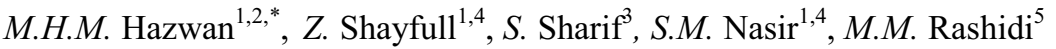 \\ ${ }^{1}$ School of Manufacturing Engineering, Universiti Malaysia Perlis, Kampus Tetap Pauh Putra, 02600 \\ Arau, Perlis, Malaysia. \\ ${ }^{2}$ School of Engineering Technology, Universiti Malaysia Perlis, Kampus UniCITI Alam, Sungai \\ Chuchuh, 02100 Padang Besar, Perlis, Malaysia. \\ ${ }^{3}$ Faculty of Mechanical Engineering, Universiti Teknologi Malaysia, 81310 UTM Skudai, Johor, \\ Malaysia. \\ ${ }^{4}$ Green Design and Manufacture Research Group, Centerof Excellence Geopolymer and Green \\ Technology (CEGeoGTech), Universiti Malaysia Perlis, 01000 Kangar, Perlis, Malaysia. \\ ${ }^{5}$ Faculty of Mechanical Engineering, Universiti Malaysia Pahang, 26600 Pekan, Pahang, Malaysia.
}

\begin{abstract}
Today, there are many of optimisation method have been explored by previous researchers to find the appropriate processing parameters setting for the injection moulding process. From the previous researches, it has been proven that the optimisation work improved the quality of the moulded part. However, the application of optimisation work in conformal cooling channels still lacks. Therefore, in this study, the application of optimisation work to improve warpage of front panel housing with conformal cooling channels moulds have been explored. By choosing cooling time, coolant temperature, packing pressure and melt temperature as the variable parameters, design of experiment (DOE) has been defined by using the rotatable central composite design (CCD) approach. Response Surface Methodology (RSM) was performed to determine the mathematical model. The mathematical model then will be used in Glowworm Swarm Optimisation (GSO) method in order to obtain the optimal processing parameters setting which will optimise the warpage condition. Based on the results, cooling time is the most significant factor contributes to the warpage condition and warpage have optimised by $38.7 \%$ after optimisation using the proposed approach. This finding shows that the application of conformal cooling channels with optimisation work will produce better quality of the moulded part.
\end{abstract}

\section{Introduction}

Injection moulding process consists into four main stages which are filling, packing, cooling and ejecting processes $[1,2]$. Due to the complexity of injection moulding process, it is

\footnotetext{
*Corresponding author: hazwanhanid@unimap.edu.my
} 
difficult for injection moulding industries in order to produce the best quality of the moulded part. Most common defects in injection moulding is a warpage [3]. Warpage is difficult to avoid due to design complexity and numerous of influence factors which affect the assembly process because of uneven clearance or interference problems. With an appropriate setting of injection moulding processing parameters, warpage condition can be reduced [4]. Previously, most of injection moulding industries have used try-and-error approach in order to obtain an appropriate processing parameters setting which consume time and production cost [5]. Today, with the advancement of computer technology, an appropriate combination of processing parameters can be obtained by simulation analysis software with and aid of optimisation approach which is highly accurate, shorter time, and cost effective [3]. These days, many researchers came with various proposals of optimisation approaches to determine an optimal processing parameters in order to optimise the quality of injection moulded parts.

For instances, Wang et al. [6], studied in minimising warpage on cellular phone cover made from PC and ABS material. Expected improvement (EI) optimisation method has been proposed in this research with the aid of Kriging surrogate model and genetic algorithm (GA). At first, the moulded part have been simulated to determine the initial condition. Then, Kriging surrogate model was employed to obtain the mathematical model. Next, the EI method with the combination of GA was performed to find the optimum processing parameters and to obtain the significant factor that contribute to warpage. The results show that warpage reduced up to $28.24 \%$ and packing pressure has detected as the significant factor contributed to warpage.

Chen et al. [7], explored the sequential optimisation methods which are Taguchi's method, hybrid back-propagation neural network and genetic algorithm (BPNN-GA) and hybrid back-propagation neural network and particle swarm optimisation (BPNN-PSO) to find an optimum length and to reduce warpage. ADSL modem cover made of PA-765 material was used as a specimen in this research. At first, Taguchi's method was conducted to investigate the initial processing parameters. Next, by implementing ANOVA, packing pressure and packing time have been found as the significant factors that contributed to the length and warpage condition. Then, BPNN-GA was conducted to obtain the first stage of optimal processing parameters setting. From the first stage analysis, BPNN-PSO was performed to obtain the second stage of optimal processing parameters and the results show that warping have been reduced by $38,6 \%$, from $0.2202 \mathrm{~mm}$ to $0.1351 \mathrm{~mm}$ and optimal length achieved by $123.997 \mathrm{~mm}$ from target value which is $124 \mathrm{~mm}$.

Gang Xu and Zhitao Yang [8], investigated the sequence of optimisation methods consist of Taguchi's method, back-propagation neural networks (BPNN), grey correlation analysis (GCA) and particle swarm optimisation (PSO) in order to improve the part weight, flash and volumetric shrinkage on the thin-walled part which made of PP material. At first, Taguchi's method was used to identify significant processing parameters. Then, GCA was performed to establish the hidden neuron numbers of BPNN. Next, the BPNN was used to generate the optimisation algorithm. Then, this algorithm has been used by PSO to get optimal outcomes. The results of local optimisation show that part weight was improved by $30 \%$, flash improved by $46 \%$ and volume shrinkage reduced by $53 \%$. Meanwhile, global optimisation results show that part weight was improved by $28 \%$, flash improved by $48 \%$, and volume shrinkage reduced by $41 \%$.

Based on the literatures, moulded part qualities can be enhanced by the application of optimisation work. However, most of previous researches focused an optimisation work on conventional straight-drilled cooling channels. Nowadays, there are some researchers have introduced the various of conformal cooling channels design which have been proven improved quality and productivity of the moulded part.

For instance, Gao et al. [9], analysed the cooling effect of conformal cooling channels (CCC). By using a plastic cup as a moulded part, the performance of conformal cooling 
channels has been carried out and compared with conventional cooling channels by using Autodesk Moldflow Insight software. The simulation results show that cooling time have been reduced from $11.34 \mathrm{~s}$ to $8.284 \mathrm{~s}$ compared with conventional cooling channels. Average temperature also have been decreased which is from $75.56^{\circ} \mathrm{C}$ to $58.67^{\circ} \mathrm{C}$ and warping deformation by using the proposed conformal cooling channels have been reduced from $0.6417 \mathrm{~mm}$ to $0.5752 \mathrm{~mm}$.

Saifullah and Masood [10], evaluated the performance of conformal cooling channels compared with conventional cooling channels of a moulded circular plastic bowl made from PP. The cooling channel diameter was $12 \mathrm{~mm}$ and have been located as close as possible with the surface of core and cavity that in contact with the melted plastic. ANSYS thermal analysis software has been performed to evaluate the performance of conformal cooling channels and compared it with conventional cooling channels. The results show that conformal cooling channels give more uniformity of temperature distribution in the moulding process and cooling time has been reduced about $20 \%$ of the total cycle duration compared to conventional cooling channels.

Based on the previous conformal cooling channels researches, the application of optimisation approach in order to determine an appropriate processing parameters setting are still lacking. Therefore, this study will be introduced an alternative optimisation approach to improve warpage on front panel housing part made of Acrylonitrile-Butadiene-Styrene (ABS) with Milled Groove Square Shape (MGSS) conformal cooling channels mould. Based on input processing parameters, design of experiment (DOE) will be generated by using full factorial Design (FFD) with an aid of rotatable central composite design of experiment (CCD). Then AMI 2013 software will be used to analyse warpage condition for each run. Response surface methodology (RSM) will be performed in order to obtain the mathematical model function and analysis of variance (ANOVA) will be used to determine the significant factors influencing the warpage condition. The mathematical model obtained from RSM will be used in glowworm swarm optimisation (GSO) method as an objective function to determine the optimal processing parameters which will optimise the warpage of the moulded part.

\section{Response surface methodology}

Response surface methodology (RSM) is a classical optimisation approach. It was used to demonstrate the relationship between variable parameters which influence the response condition in two or three-dimensional hyperbolic surface[11]. The mathematical model function will be obtained by using the second-order polynomial regression model in this study which will be used as the objective function in GSO. The necessary information to construct the response model was accumulated by the simulation analysis [12, 13]. Figure 1 shows the RSM flowchart in this study. 


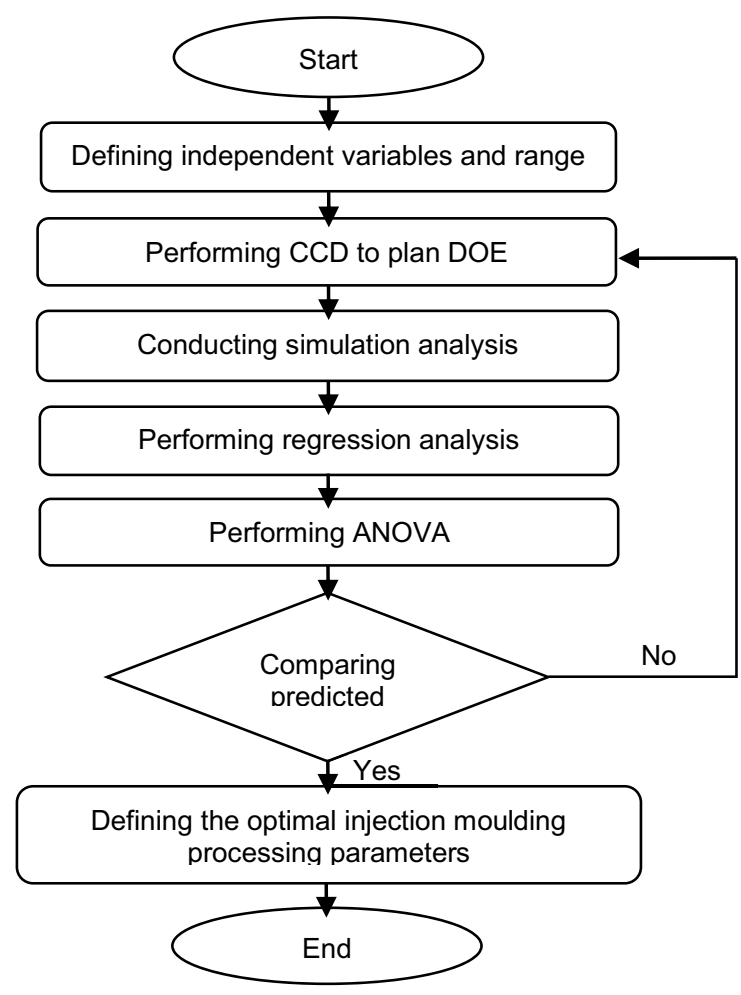

Fig. 1. Response Surface Methodology (RSM) flowchart

\subsection{Design of experiment setup}

In this study, coolant temperature, melting temperature, packing pressure and cooling time have been selected as variable parameters and the range of each parameter was shown in Table 1. At first, full factorial design (FFD) with four centre points was selected as an experimental design to evaluate the model and main effects contribute to the warpage condition by using Design Expert 7.0 software. In order to obtain the significant curvature which is important in the RSM regression analysis, the augment of rotatable central composite design (CCD) was added. Therefore, 30 runs of specified condition have been generated and each run will be set in AMI 2013 simulation software to evaluate the warpage condition of the moulded part.

Table 1. Variable parameters and levels

\begin{tabular}{|c|c|c|}
\hline \multirow{2}{*}{ Factors } & \multicolumn{2}{|c|}{ Level } \\
\cline { 2 - 3 } & Minimum & Maximum \\
\hline Coolant inlet temperature, $\mathrm{A}\left({ }^{\circ} \mathrm{C}\right)$ & 25 & 65 \\
\hline Melt temperature, $\mathrm{B}\left({ }^{\circ} \mathrm{C}\right)$ & 220 & 260 \\
\hline Packing pressure, $\mathrm{C}(\mathrm{MPa})$ & 46.74 & 56.74 \\
\hline Cooling time, $\mathrm{D}(\mathrm{s})$ & 10 & 25 \\
\hline
\end{tabular}

\subsection{Finite element analysis setup}

The CAE software, Autodesk Moldflow Insight (AMI) 2013 have been used to simulate the injection moulding process and to evaluate the warpage condition of front panel housing moulded part which has $2.5 \mathrm{~mm}$ of average thickness and made from ABS material with trade 
name as Toray/Toyolac 700-314 with MGSS conformal cooling channels mould as shown in Fig. 2. The moulded part, gating system and cooling channels $3 \mathrm{D}$ data was created and imported into the software for meshing process. In order to obtain more precise results, the mould insert material made of P20 steel and Nissei NEX1000, 80 tonne injection moulding machine specification have been set in the AMI software. Then, the Cool (FEM)+Fill+Pack+Warp analysis has been performed to evaluate warpage condition for each run which have been generated by DOE.

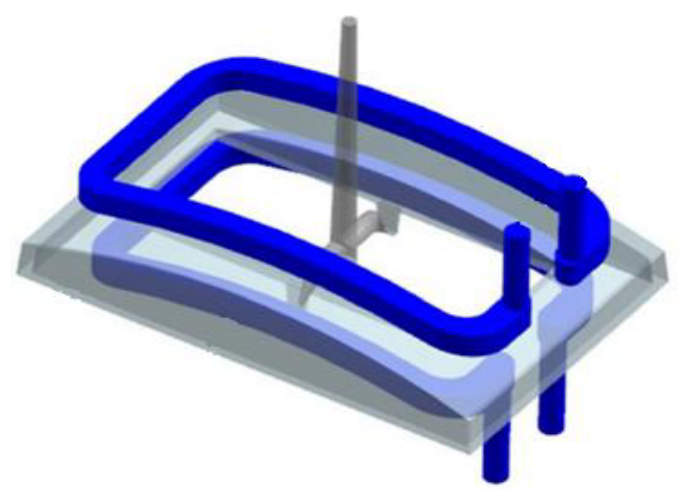

Fig. 2. Front panel housing with MGSS conformal cooling channels

\subsection{RSM regression analysis}

The warpage results for each run which obtained from the simulation analysis will be used in the RSM regression analysis. By using Design Expert 7.0 software the regression analysis was performed with the backward quadratic model in order to obtain the mathematical model function which representing the relationship between variable parameters and response. The software will calculate using second-order polynomial regression model in the statistically manner and the results will be verified with ANOVA.

\subsection{Analysis of variance (ANOVA)}

The result of the quadratic model obtained from the RSM regression analysis will be verified by analysis of variance (ANOVA) to determine either the mathematical model was statistical significant or otherwise. In the same analysis, the significant factors that contribute to the warpage condition will be defined.

\section{Glowworm swarm optimisation}

The operators in GSO are recognised as glowworms [14] that carry a luminescent amount which have been called as luciferin [15]. Every glowworm utilises an artificial proportional luciferin to transmit the fitness of its current location and evaluate based on the objective model function to its neighbours. The glowworms rely on the variable of their neighbourhood which is based on the radial sensor range boundary in order to identify their neighbours and evaluate their movements. Each glowworm, use the probabilistic mechanism by selecting a neighbour that contain the higher luciferin amount than its own and moves toward it. In other words, it will be attracted to the neighbours which is glowing brighter. Finally, the movement of the glowworms will be based on the local information and particular neighbour 
interactions which empower the majority swarm to form multiple optima of a given multimodal function.

In this study, GSO method will be carried out to obtain the optimal processing parameters of injection moulding process based RSM mathematical model function. MATLAB R2014a software will be used to conduct GSO analysis. Figure 3 shows the flowchart of GSO in this study.

\subsection{Defining mathematical model function}

The objective function used in GSO is the mathematical model function which have been obtained from RSM regression analysis. The formulated objective function has been taken in this study is a warpage function.

\subsection{Initialisation of glowworms' parameters}

The initial glowworms' parameters were set based on the selected injection moulding variable parameters limit in this study to create the solution space. Then, the GSO agents will be deployed randomly in the solution space by setting the initial glowworms population size and maximum iteration based on the research requirement. In this study 30 numbers of glowworms and 40 iterations have been set.

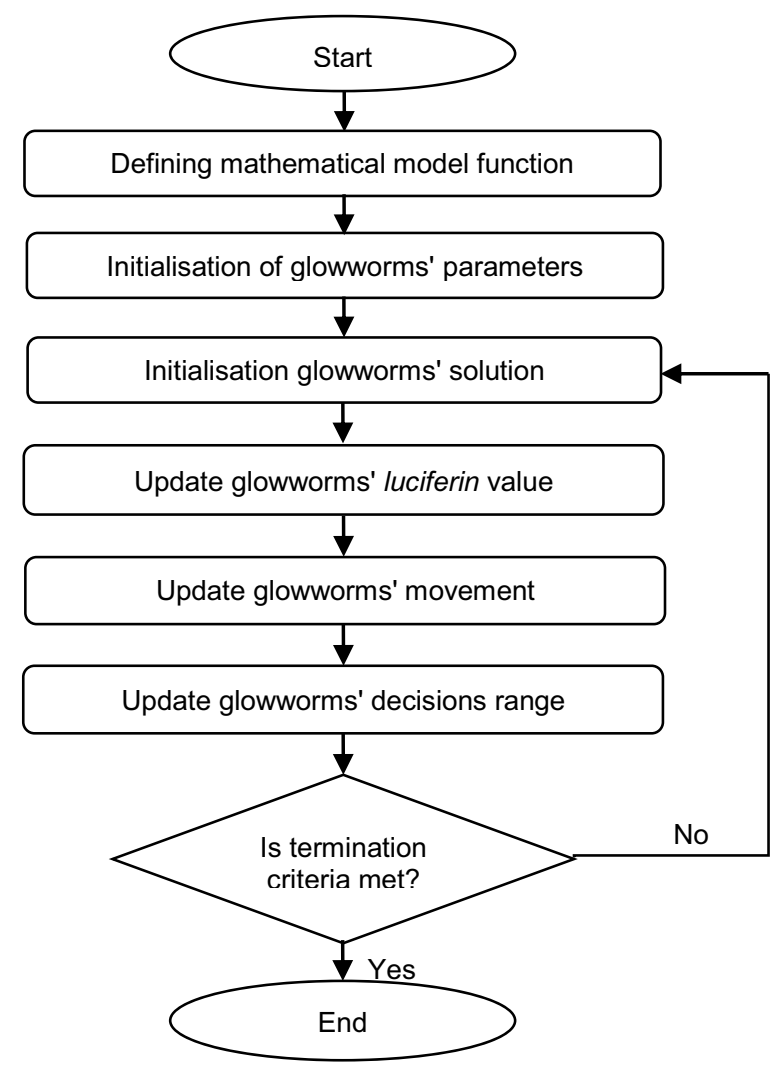

Fig. 3. Flowchart of Glowworm Swarm Optimisation (GSO) 


\subsection{Initialisation glowworms' solution}

The initial solution of initial luciferin value $\left(l_{o}\right)$, luciferin decay constant $(\rho)$, luciferin enhancement constant $(\gamma)$, beta $(\beta)$, step size $(s)$, neighbourhood range $r_{d}^{i}(t)$ and parameter used to control the number of neighbours $\left(n_{t}\right)$ was set based on the research requirement where each glowworm contained the same luciferin value and sensor range in this phase. In this study, GSO control parameters optimal setting are: $\beta=0.08, \rho=0.4, \gamma=0.6$ and $r_{d}^{i}(t)=3$.

\subsection{Update glowworms' luciferin value}

At the beginning, each glowworm contains the same luciferin value. Influenced by the objective function value of their current location, the luciferin value will be changed. The rule of luciferin update was given by standard Equation (1) where $l i(t)$ is the luciferin level for glowworm $i$ at time $t, \rho$ is the luciferin decay constant $(0<\rho<1)$, and $J i(t)$ indicates the objective function at agent $i$ 's location at time $t$.

$$
l i(t+1)=(1-\rho) l i(t)+\gamma J i(t+1)
$$

\subsection{Update glowworms' movement}

In the movement-update phase, each glowworm will move toward neighbour that contained the higher luciferin value than its own using a probabilistic mechanism. The probability of agent $i$ move to agent $j$ was given by a standard Equation (2) where $l_{i}(t)$ is the luciferin value for glowworm $i, d(i, j)$ is the Euclidean distance between agent $i$ and $j$.

$$
P_{i j}(t)=\frac{l_{j}(t)-l_{i}(t)}{\sum_{k \in N_{i}(t)} l_{k}(t)-l_{i}(t)}
$$

Then, the glowworm $i$ movement can be expressed by Equation (3) where $s$ is the step size.

$$
x_{i}(t+1)=x_{i}(t)+s\left[\frac{x_{j}(t)-x_{i}(t)}{\left\|x_{j}(t)-x_{i}(t)\right\|}\right]
$$

\subsection{Update glowworms' local decisions range}

Local decision range update phase will be used to determine multiple peaks in a multimodal functional landscape in order to obtain the optimal variable parameters which optimise warpage value effectively. When the number of neighbours changed, the local decision domain needs to update in each of iteration. The rule is given by Equation (4) where $r_{d}^{i}(t+1)$ is the local decision domain of glowworm $i$ in the $t+1$ iteration, $\beta$ is the constant parameter that affected the rate of change of the neighbour domain and $n_{t}$ is the threshold used to control the number of neighbours.

$$
r_{d}^{i}(t+1)=\min \left\{r_{s}, \max \left\{0, r_{d}^{i}(t)+\beta\left(n_{t}-\left|N_{i}(t)\right|\right)\right\}\right\}
$$




\section{Results and discussions}

\subsection{Injection Moulding Process Simulation}

Warpage values obtained from simulation analysis are shown in Table 2. The results tabulate the warpage value for each run with the specified variable parameters condition which obtained from the DOE. The specified variable parameters condition was set and simulated in the AMI 2013 software.

Table 2. Injection moulding process simulation results.

\begin{tabular}{|c|c|c|c|c|c|c|}
\hline \multirow[b]{2}{*}{$\begin{array}{c}\text { Standard } \\
\text { Order }\end{array}$} & \multirow[b]{2}{*}{$\begin{array}{l}\text { Data } \\
\text { Source }\end{array}$} & \multicolumn{4}{|c|}{ Variable parameters for injection moulding simulation } & \multirow{2}{*}{$\begin{array}{c}\text { Response } \\
\text { Warpage } \\
(\mathrm{mm})\end{array}$} \\
\hline & & $\begin{array}{c}\text { Coolant } \\
\text { temperature } \\
\left({ }^{\circ} \mathrm{C}\right)\end{array}$ & $\begin{array}{c}\text { Melt } \\
\text { temperature } \\
\left({ }^{\circ} \mathrm{C}\right) \\
\end{array}$ & $\begin{array}{c}\text { Packing } \\
\text { Pressure } \\
(\mathrm{MPa})\end{array}$ & $\begin{array}{l}\text { Cooling } \\
\text { time (s) }\end{array}$ & \\
\hline 1 & \multirow{16}{*}{ DOE } & 25 & 220 & 46.74 & 10 & 0.115 \\
\hline 2 & & 65 & 220 & 46.74 & 10 & 0.095 \\
\hline 3 & & 25 & 260 & 46.74 & 10 & 0.165 \\
\hline 4 & & 65 & 260 & 46.74 & 10 & 0.125 \\
\hline 5 & & 25 & 220 & 56.74 & 10 & 0.110 \\
\hline 6 & & 65 & 220 & 56.74 & 10 & 0.090 \\
\hline 7 & & 25 & 260 & 56.74 & 10 & 0.155 \\
\hline 8 & & 65 & 260 & 56.74 & 10 & 0.130 \\
\hline 9 & & 25 & 220 & 46.74 & 25 & 0.095 \\
\hline 10 & & 65 & 220 & 46.74 & 25 & 0.085 \\
\hline 11 & & 25 & 260 & 46.74 & 25 & 0.155 \\
\hline 12 & & 65 & 260 & 46.74 & 25 & 0.115 \\
\hline 13 & & 25 & 220 & 56.74 & 25 & 0.085 \\
\hline 14 & & 65 & 220 & 56.74 & 25 & 0.090 \\
\hline 15 & & 25 & 260 & 56.74 & 25 & 0.140 \\
\hline 16 & & 65 & 260 & 56.74 & 25 & 0.115 \\
\hline 17 & \multirow{4}{*}{ Centre } & 45 & 240 & 51.74 & 17.5 & 0.125 \\
\hline 18 & & 45 & 240 & 51.74 & 17.5 & 0.125 \\
\hline 19 & & 45 & 240 & 51.74 & 17.5 & 0.125 \\
\hline 20 & & 45 & 240 & 51.74 & 17.5 & 0.125 \\
\hline 21 & \multirow{10}{*}{ Axial } & 5 & 240 & 51.74 & 17.5 & 0.130 \\
\hline 22 & & 85 & 240 & 51.74 & 17.5 & 0.090 \\
\hline 23 & & 45 & 200 & 51.74 & 17.5 & 0.050 \\
\hline 24 & & 45 & 280 & 51.74 & 17.5 & 0.155 \\
\hline 25 & & 45 & 240 & 41.74 & 17.5 & 0.120 \\
\hline 26 & & 45 & 240 & 61.74 & 17.5 & 0.130 \\
\hline 27 & & 45 & 240 & 51.74 & 2.5 & 0.140 \\
\hline 28 & & 45 & 240 & 51.74 & 32.5 & 0.110 \\
\hline 29 & & 45 & 240 & 51.74 & 17.5 & 0.125 \\
\hline 30 & & 45 & 240 & 51.74 & 17.5 & 0.125 \\
\hline
\end{tabular}

\subsection{Response surface methodology (RSM) regression analysis}

From regression analysis, the determination coefficient, R2 that fits the model is 0.9774 . The adjusted determination is 0.9655 , which shows the regression model is significant with an adequate precision is more than 4 , which is 38.862 . The model is more significant if $R 2$ value is closer to 1 [16]. The standard deviation for this model is $4.683 \times 10-3$ and this value indicate that it is relatively lower than 0.05 which is good for better precision and reliability of the experiment [17]. The polynomial regression model which related to the warpage with all input parameters (coolant inlet temperature (A), melt temperature (B), packing pressure $(\mathrm{C})$ and cooling time (D) is established by Design Expert 7 software represented in Equation 5. This mathematical model function will be used in GSO as an objective function. 


$$
\begin{aligned}
\text { Warpage }= & -0.979+\left(1.763 \times 10^{-3} A\right)+\left(8.342 \times 10^{-3} B\right)-\left(1.391 \times 10^{-3} C\right) \\
& -\left(1.573 \times 10^{-3} D\right)-\left(1.328 \times 10^{-5} A B\right)+\left(2.8125 \times 10^{-5} A C\right) \\
& +\left(1.458 \times 10^{-5} A D\right)-\left(9.082 \times 10^{-6} D^{2}\right)-\left(1.377 \times 10^{-5} B^{2}\right)
\end{aligned}
$$

\subsection{Analysis of Variance (ANOVA)}

From the ANOVA table as shown in Table 3, the F calculated value is bigger than $\mathrm{F}$ tabulated. This condition shows that the mathematical model obtained from regression analysis was significant. The ANOVA also indicated that three from four selected variable parameters give significant effect on the warpage condition.

Table 3. ANOVA of response surface model.

\begin{tabular}{|c|c|c|c|c|c|c|c|}
\hline & $\begin{array}{c}\text { Sum of } \\
\text { Squares }\end{array}$ & df & $\begin{array}{c}\text { Mean } \\
\text { Square }\end{array}$ & $\begin{array}{c}\text { F } \\
\text { (calculated) }\end{array}$ & $\mathrm{R}^{2}$ & RA $^{2}$ & $\begin{array}{c}\mathrm{F} \\
\text { (tabulated) }\end{array}$ \\
\hline SSR & 0.0180 & 10 & 0.0018 & 82.1355 & 0.9774 & 0.9655 & 2.37 \\
\hline SSE & 0.0004 & 19 & 0.0000 & & & & \\
\hline Total & 0.0184 & 29 & & & & & \\
\hline
\end{tabular}

The results show that cooling time was the most significant factor contributed to the warpage condition. This result was inline with previous researchers which found out the same significant factor which influenced the warpage condition $[18,19]$. Then, it follows by cooling temperature and melt temperature. Packing pressure was the least significant factor contributed to the warpage condition for MGSS conformal cooling channels as shown in Figure 4. In addition, this result proves that MGSS conformal cooling channels give better uniformity of thermal distribution in the mould insert where the temperature is no longer become the most significant factor contribute to the warpage condition.

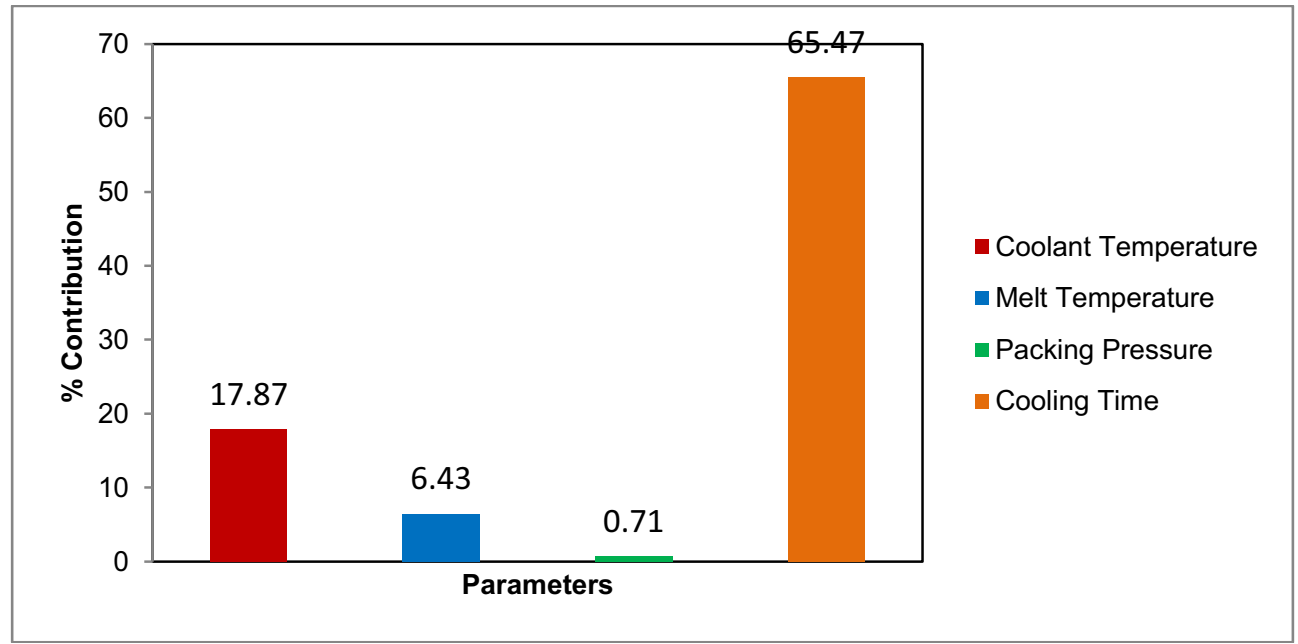

Fig. 4. Contribution for each parameters in percentage.

Equation 5 was applied to calculate the prediction warpage values of the polynomial model and the results is summarised in Figure 5. From the comparison, it shows that the simulation and predicted value are very close to each other which indicated the mathematical response function have given a good prediction value in estimating warpage. 


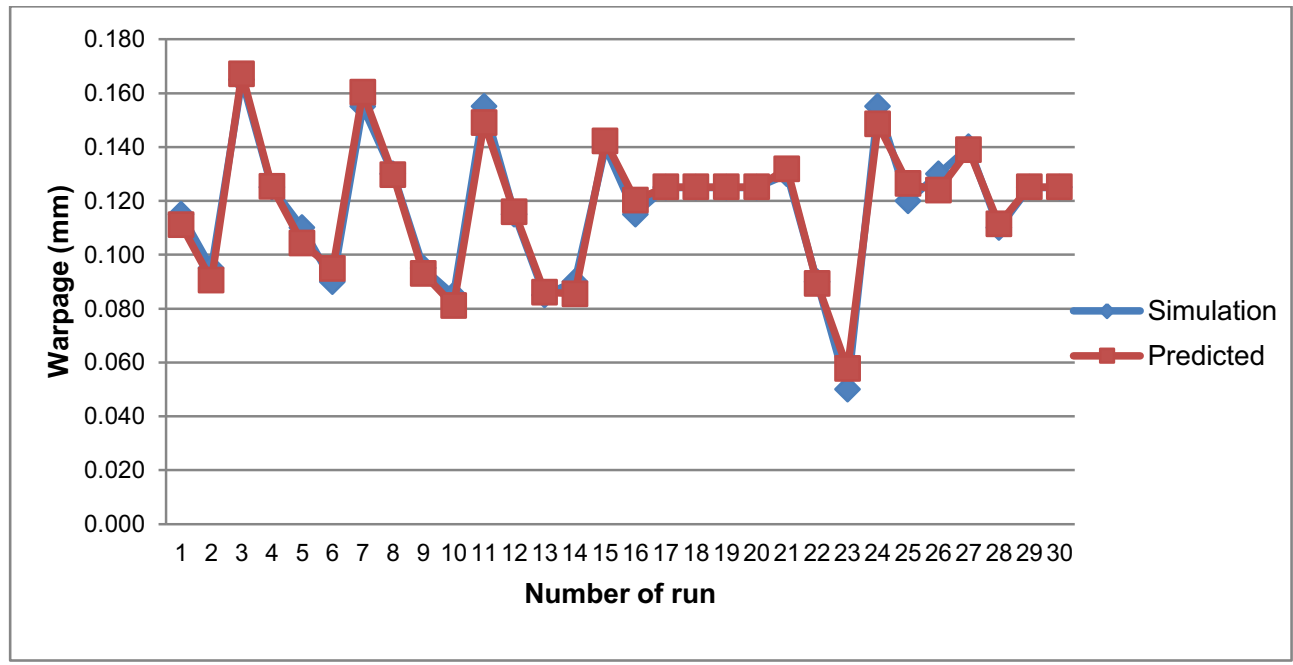

Fig. 5. Simulation and predicted warpage comparison

\subsection{Glowworm Swarm Optimisation (GSO) analysis}

The GSO algorithm has been conducted on injection moulding processing parameters. The algorithm was tested on four selected variable parameters. By using the mathematical model function obtained from RSM, the optimal results were shown in Table 4 and the warpage variation for each glowworm was shown in Figure 6.

Table 4. Recommended simulation results versus GSO Optimised results

\begin{tabular}{|c|c|c|}
\hline Factors & $\begin{array}{c}\text { Recommended } \\
\text { simulation } \\
\text { results }\end{array}$ & $\begin{array}{c}\text { GSO optimised } \\
\text { results }\end{array}$ \\
\hline Coolant inlet temperature, A $\left({ }^{\circ} \mathrm{C}\right)$ & 25 & 43.01 \\
\hline Melt temperature, B $\left({ }^{\circ} \mathrm{C}\right)$ & 240 & 222.54 \\
\hline Packing pressure, $\mathrm{C}(\mathrm{MPa})$ & 46.74 & 50.33 \\
\hline Cooling time, D $(\mathrm{s})$ & 10.55 & 24.85 \\
\hline Warpage, $(\mathrm{mm})$ & 0.155 & 0.095 \\
\hline
\end{tabular}




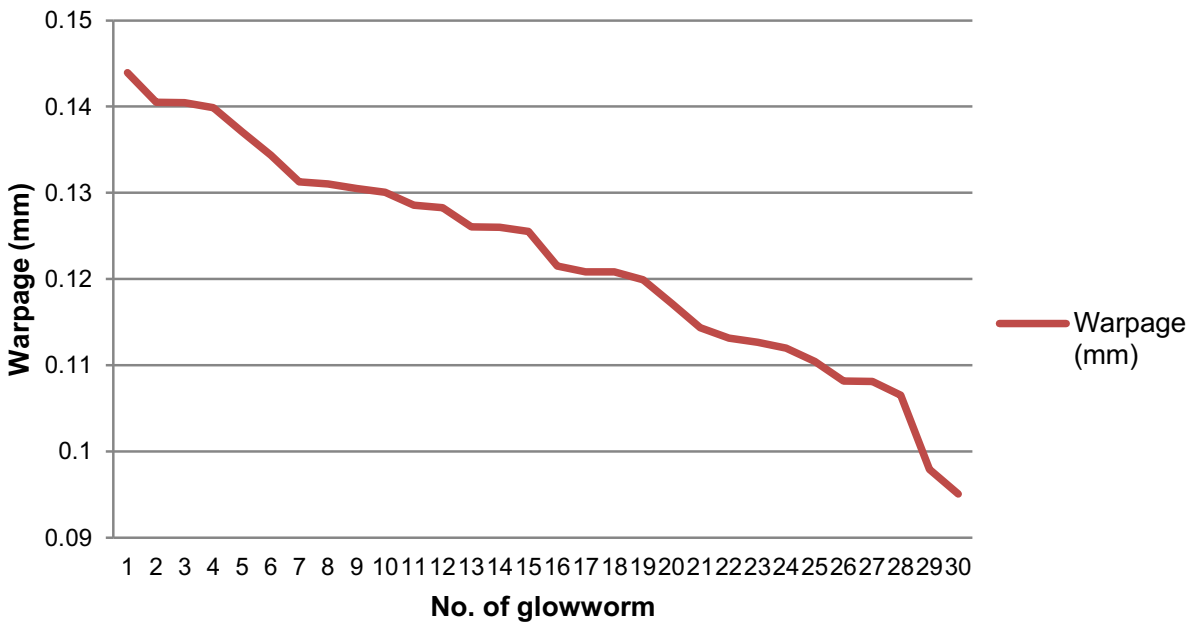

Fig. 6. Warpage variation for each glowworm

\section{Conclusion}

This study is definitely helpful in enhancing the quality of moulded parts produced where the objective is to optimise warpage of the front panel housing moulded part with MGSS conformal cooling channels mould have been achieved. Based on the results, the warpage has been optimised by using an alternative approach of response surface methodology (RSM) and Glowworm Swarm Optimisation (GSO). The results also show that:

- By using RSM, the significant mathematical model function can be obtained in order to predict warpage value with reasonable accuracy.

- From the ANOVA results, cooling time is the most significant factor influencing the warpage condition on the moulded part, follow by coolant temperature and melt temperature.

- The optimal processing parameter obtained from a GSO optimising warpage by $38.7 \%$ which is from $0.155 \mathrm{~mm}$ from the simulation result to $0.095 \mathrm{~mm}$.

In this study, it proved that the application of conformal cooling channels with the proposed optimisation approach has enormous potential in order to obtain better quality of moulded parts.

\section{References}

1. W. Michaeli, G. Potsch, Injection molding: an introduction, München: Hanser, Fachbuchverlag, 1995.

2. L. Sors, I. Balazs, Design of plastic moulds and dies, 1989.

3. S.S. Teklehaimanot, Simulation and design of a plastic injection Mold, 2012.

4. D. Annicchiarico, J.R Alcock, Mater. Manuf. Process, 29, (6), 662, (2014).

5. Y.C. Lam, L.Y. Zhai, K. Tai, S.C. Fok, Int. J. Prod. Res., 42, (10), 2047, (2004).

6. X. Wang, J. Gu, C. Shen, X. Wang, Int. J. Adv. Manuf. Tech., 78, (1-4), 177, (2015).

7. W.C Chen, P.H. Liou, S.C. Chou, Int. J. Adv. Manuf. Tech., 73, (9-12), 1465, (2014).

8. G. Xu, Z. Yang, Int. J. Adv. Manuf. Tech., 78, (1-4), 525, (2015). 
9. G.Q. Gao, Y.S. Liu, Y.J. Cai, Analysis and Manufacturing of Conformal Cooling Channels in Injection Mold, (Trans. Tech. Publ.), 2014.

10. A. Saifullah, S. Masood, Finite element thermal analysis of conformal cooling channels in injection moulding, (Engineers Australia), 2007.

11. D. Montgomery, Design and Analysis of Experiments, (6th edn.,) John Wiley and Sons', New York, NY, 2005.

12. H. Oktem, T. Erzurumlu, H. Kurtaran, J. Mater. Process. Technol., 170, (1), 11, (2005).

13. B. Ozcelik, T. Erzurumlu, Int. Commun. Heat Mass, 32, (8), 1085, (2005).

14. E. Bonabeau, M. Dorigo, G. Theraulaz, Swarm intelligence: from natural to artificial systems, (Oxford university press), 1999.

15. R. Brits, A.P. Engelbrecht, F. Van den Bergh, A niching particle swarm optimizer, (Singapore: Orchid Country Club), 2002.

16. Y.H. Wang, J.T. Feng, Q. Zhang, X. Zhang, J. Appl. Microbiol, 104, (3), 735, (2008).

17. M.S. Tanyildizi, D. Ozer, M. Elibol, Process Biochem, 40, (7), 2291, (2005).

18. W.C. Chen, D. Kurniawan, Int. J. Precis. Eng. Manuf., 15, (8), 1583, (2014).

19. W.C. Chen, M.H. Nguyen, W.H. Chiu, T.N. Chen, P.H. Tai, Int. J. Adv. Manuf. Technol., 83, (9-12), 1873, (2016). 